\title{
Does salary affect the choice of residency in non-university teaching hospitals? A panel analysis of Japan Residency Matching Programme data
}

\author{
Taiji Enari and Hideki Hashimoto*
}

\begin{abstract}
Background: Previous studies have investigated factors that are influential on the choice of training hospitals among residency physicians, but the effect of salary was not conclusive. In this study, we aimed to examine whether a higher salary attracted more residents to non-university hospitals participating in the Japanese Residency Matching Programme.

Methods: Data on 475 hospitals/programmes between 2006 and 2009 were available for analysis. We first conducted an ordinary least squares regression analysis on the ratio of the number of applicants to the residency programme quota as an index of resident's choice, for comparison with previous studies. We further performed panel data analysis to better control for unobserved heterogeneity across hospitals, which could be confounded by the amount of salary. We also performed stratified analysis by the population size of the hospital location.

Results: In ordinary least squares regression, salary showed a positive, but not significant association, with the ratio of the number of applicants to the programme quota, while the results of a fixed effect model exhibited a positive and significant effect of salary $(\varepsilon=0.4995, P=0.015)$ on the ratio. Analysis stratified by city size showed that the elasticity of salary was comparable ( $\varepsilon=1.9089, P=0.016$ in large cities versus $\varepsilon=1.9185, P=0.008$ in small cities), while that of the number of teaching physicians was larger in large cities $(\varepsilon=1.9857, P=0.009)$ compared with that in small cities $(\varepsilon=1.6253, P=0.033)$. The number of teaching physicians had a significant and negative effect modification on salary, implying an antagonistic effect between these two attributes $(\varepsilon=-1.5223, P=0.038)$.

Conclusions: Our results indicate that the amount of salary influences the choice of training hospitals among medical graduates who choose non-university settings. Use of a monetary reward in a residency programme could be a feasible tactic for hospitals to attract residents.
\end{abstract}

Keywords: Residency programme, Economic incentive, Matching programme, Japan

\section{Background}

The mal-distribution of physicians is a common problem not only in developed countries, but also in middle income and developing countries [1-9]. Possible political solutions to expand physicians to underserved areas are much discussed, such as increasing the supply of physicians, reforming career selection and professional training system, compulsory duties, and preparing incentives to serve in underserved areas [10]. Several studies have

\footnotetext{
* Correspondence: hidehashimoto-circ@umin.ac.jp
Department of Health Economics and Epidemiology Research, School of
Public Health, The University of Tokyo, 7-3-1 Hongo, Bunkyo-ku, Tokyo * Correspondence: hidehashimoto-circ@umin.ac.jp
Department of Health Economics and Epidemiology Research, School of
Public Health, The University of Tokyo, 7-3-1 Hongo, Bunkyo-ku, Tokyo

* Correspondence: hidehashimoto-circ@umin.ac.jp
Department of Health Economics and Epidemiology Research, School of
Public Health, The University of Tokyo, 7-3-1 Hongo, Bunkyo-ku, Tokyo 113-0033, Japan
} (13-0033, Japan

\section{() Biomed Central}

(c) 2013 Enari and Hashimoto; licensee BioMed Central Ltd. This is an Open Access article distributed under the terms of the Creative Commons Attribution License (http://creativecommons.org/licenses/by/2.0), which permits unrestricted use, distribution, and reproduction in any medium, provided the original work is properly cited. shown that increasing the supply of physicians falls short of a solution to the problem, but rather exacerbates the unequal distribution of physicians [2,10-12]. Instead, financial incentives have been regarded as more effective strategies to attract physicians in underserved areas, though they may not solve the whole issue of maldistribution of the physicians [6,10,13-15].

Many studies have demonstrated that monetary incentives are influential on a physician's career choice of subspecialties, such as paediatrics [16], emergency medicine [17], internal medicine $[18,19]$, surgery [20], primary care [21,22], and being a general practitioner [23]. A previous study in the USA showed that the effect of concerns on 
lifestyle and income has increased over time in the career choice among new medical school graduates [24]. In Japan, Kawamura [25] performed one of the first studies to empirically assess influential factors of residency choice among new graduates. Using a multivariable regression model, this previous study concluded that salary was a significantly influential factor among those who chose university hospitals, while non-economic factors, such as the number of supervising doctors, were influential among those who chose non-university hospitals.

However, it is premature to conclude from Kawamura's study [25] that the effect of payment conditions for residency choice is limited to those residents in university hospitals. In fact, according to Kawamura, the salary for 2 years in university hospitals was 6478000 yen (\$80 975 at the exchange rate of $1 \mathrm{USD}=80 \mathrm{JPY}$ ) on average, compared with 9115000 yen (\$113938) in non-university hospitals [25]. Lower salaries in university hospitals were often attributed to authoritarian influence by clinical departments in medical schools on young trainees' future career paths in affiliated hospitals [26]. Therefore, it is possible that a young graduate's choice of non-university hospitals in his/ her early career is already affected by incentives other than authoritative reasons, including economic incentives related to annual salary.

According to a questionnaire survey conducted by the Ministry of Health, Labour, and Welfare (MHLW), 27.1\% of residents who chose non-university hospitals answered that salary and work environment affected their choice of training hospitals [27]. Nomura et al. also conducted a questionnaire survey among second-year residents, and reported that those who chose non-university hospitals were more satisfied with a higher income [28].

A wide variation in the annual salary, even among nonuniversity hospitals, has been reported, with five- to six-fold difference between the top and bottom salaries [29]. The amount of salary is determined endogenously based on conditions in hospitals, such as location, university affiliation, teaching status, and size. Therefore, the effect of income on specialty choice might have been underestimated in previous studies because the amount of salary was treated as an exogenous variable. Hay showed that a significant effect of income on the choice of specialty was observed only when the simultaneously determined supply and demand of the specialty were counted by using a twostaged logit-ordinary least squares (OLS) estimator [30].

The objective of the current study was to identify whether the improved payment conditions affected a medical graduate's choice of residency programme in Japan. We re-investigated the effect of annual salary on the hospital choice of medical graduates using a different approach. First, we limited our analysis to non-university hospitals because the distribution of salaries is different between university and non-university hospitals. In fact, salaries paid in university hospitals are homogenous across institutes because of regulatory reasons due to the governmental subsidy. The salaries in university hospitals have also been almost constant over time since the introduction of the new residency programme as is described shortly [31]. Furthermore, the choice of university hospitals is supposedly influenced by a distinctive set of individual preferences, such as a preference for an academic career path and for home location [27]. Because data on individual preferences were not available, exclusion of university hospitals from our study sample was necessary to discriminate the effect of salary and distinctive sets of individual preferences. Additionally, because university hospitals often change their quota for residents according to the expected number of applicants, the ratio of the number of applicants to the quota, which was our target variable, is endogenously determined, and does not necessarily reflect residents' preferences in the case of university hospitals.

Second, we introduced panel data analysis to control for unobserved heterogeneity across hospitals that could be related to a hospital's decision on the amount of salary. Therefore, we hoped to overcome any bias caused by an endogenously determined annual salary, and by controlling this, we aimed to determine the actual effect of salary on a new graduate's choice of residency programme [32].

\section{Methods}

\section{New Residency Matching Programme in Japan}

In 2004, the Japanese government introduced a new Postgraduate Medical Education Programme (PGME) to improve physicians' skills in general medicine. Before 2004, medical graduates tended to seek residency positions in university hospitals affiliated with their own graduate medical schools, where the residency programme was not standardized and was often limited to subspecialty training [33]. Since the introduction of PGME, all medical graduates are obliged to take the 2-year standardized residency programme. In addition, a nationwide computerbased residency matching system called the Japan Residency Matching Programme (JRMP) started to offer medical graduates a broader range of choices, including community hospitals with new residency programmes $[34,35]$. Because the number of resident positions exceeded the number of annual medical graduates, hospitals competed with each other to attract new medical graduates through appealing to the excellence of the training programme, resulting in a considerable shift of residents from university to non-university hospitals $[28,36]$.

Another change since this reform was the payment conditions of residents. The annual salary of residents was raised, on average, up to 4.36 million yen (\$ 54500 ) after the reform in 2007 compared with 2.65 million yen (\$33 100) before the reform in 2003 [27]. We took this 
reform as a natural laboratory to test whether salary could be an incentive to attract residents.

\section{Data collection}

We obtained the number of applicants and the quota of each programme from publicly available data in the homepage of the JRMP [37]. The JRMP issues the interim and final annual reports. We used the numbers in the interim report because they better reflected the original preference of medical graduates before adjustment to the final decision. Because of data availability, we used data in 2006 and 2009 to obtain as large a sample size as possible for a balanced panel.

We obtained information on hospital characteristics from the Guidebook of Residency Programme Hospitals, which is annually published on the web site by the Foundation for Promotion of Medical Training [38,39]. This Guidebook contains information from approximately 800 teaching hospitals, including university hospitals, such as location, hospital size, the annual number of outpatients, inpatients, and emergency services, the number of medical staff and supervisor physicians, the contents of training programmes, and salary and other employment conditions for residents.

In 2006 and 2009, 1049 programmes of 944 nonuniversity hospitals, and 1051 programmes of 940 nonuniversity hospitals, respectively, participated in the JRMP. Among these, 796 programmes from 705 hospitals in 2006 and 793 programmes from 682 hospitals in 2009 provided information for the Guidebook. Because programmes were renamed, scrapped, or built over time, we manually examined the programme name, contents, and the size of the quota to match identical programmes between the 2 years. Some hospitals provided multiple programmes, although these programmes likely shared institution-specific conditions, such as hospital size and salary. Therefore, we selected one of the largest programmes per hospital. Otherwise, we used summation numbers across programmes to obtain the applicant/ quota ratio of the whole institute. We were able to match 475 pairs of programmes for further analysis. Population data from the municipalities of hospital locations were obtained from the national censuses held in 2010 [40].

\section{Study variables}

For the target variable we used the ratio of the number of applicants to the programme quota, according to a previous study [25], as an aggregated indicator of residents' choice preferences.

Our main explanatory variable was the total amount of the resident's salary throughout the 2-year residency programmes, based on Kawamura's method [25]. Extra allowance for overtime work and night shift work was not included because it was likely to depend more on the resident's duties rather than on monetary reward and the preferences of residents.

For comparative purposes, we adopted a set of covariates similar to those used in a previous study [25], such as the number of teaching physicians, hospital beds, emergency patients, and open/closed programmes within a single institution. The number of hospital beds should reflect the extent of hospital capacity and activity, which is further expected to parallel the volume and variety of inpatients with which the residents can gain experience during their training. However, because the number of hospital beds was under government regulation and was relatively constant over time, we replaced it in panel data analysis with the number of inpatients, which was more likely to vary over time. A closed programme within a single institution, compared with an open programme affiliated with other hospitals/clinics, was more likely to be provided by an institution with a wider variation of patients and more affluent educational resources, including teaching staff.

We further chose not to include several variables used in the previous study by Kawamura [25], such as the number of clinical departments and a dummy variable for the hospital's location in metropolitan cities, because these features also do not change over time. Additionally, the number of departments was not reliable as an indicator of the size and function of hospitals because of non-standardized categorization of subspecialties under the current legal regulation of hospital administration in Japan [41]. Kawamura's study [25] included the number of months for training of selective specialties in the programme as an index of programme attractiveness, but we did not include this information because it was specific to a programme rather than to a hospital.

\section{Statistical analysis}

Descriptive statistics of hospital characteristics in 2-year periods were tested with the paired $t$-test. We conducted an OLS regression in the first step to replicate the results in Kawamura's study as follows:

$$
Y_{i t}=X_{i t} \beta+\mu_{i t}
$$

where $Y_{i t}$ is the number of applicants to the quota of facility $i$ in year $t, \mathrm{X}_{i t}$ is a vector of explanatory variables including salary, and $\mu_{i t}$ is the error term. We used data from 2009 for this analysis because they were more similar to the data from 2008 used for Kawamura's analysis [25].

We further conducted panel data analysis with fixed and random effect models to eliminate the effect of unobserved heterogeneity of hospitals as follows:

$$
Y_{i t}=X_{i t} \beta+D_{i}+\varepsilon_{i t}
$$

where $\mathrm{D}_{i}$ is a vector reflecting time-consistent observed characteristics and unobserved heterogeneity of hospitals, and $\varepsilon_{i t}$ is the error term. 
Because the urbanicity of hospital location would affect the impact of income, as well as hospital size and educational environments, we also performed stratified analysis by the population size of a city where the hospital was located. We divided hospitals into two groups by the median (that is, 279,127) of the population size. We also conducted ad hoc analysis with interaction terms as described in the Results section. We first obtained OLS estimation for comparative purposes with previous studies. We then additionally conducted panel data analyses with fixed and random effect models to evaluate misspecification bias. The estimated results are presented as elasticity for comparison purposes across the strata and models.

We conducted the F-test, Hausman test, and BreuschPagan test for model specification, or to identify the best model to address the effect of unobserved heterogeneity and within-hospital variance [42]. Data were analyzed with the statistical software STATA 11 (Stata Corporation, College Station, TX, USA).

\section{Results}

Table 1 shows the descriptive statistics of the sample of hospitals included in the analysis. Over the studied period of 3 years, the salary of the 2-year residency was increased by 1.03 million yen $(\$ 12875, P<0.001)$. The number of hospital beds $(P<0.001)$, that of inpatients $(P<0.001)$, and the proportion of closed training programmes $(P<0.001)$ were significantly decreased on average over the same period. The number of teaching physicians and the average number of emergency patients were the same over this period.

Table 2 shows the results of regression models. The coefficients of variables included in the model were positive and statistically significant, but not for salary and the number of emergency patients. A larger number of teaching physicians, closed training programmes within a single institution, and a larger number of hospital beds were associated with a larger ratio of applicant number to quota.
In the fixed effect model, salary showed a significant positive effect $(\varepsilon=0.4995, P=0.015)$. The number of teaching physicians stayed significantly positive ( $\varepsilon=0.3678, P=0.004)$. The number of inpatients, replaced with that of hospital beds, also exhibited a positive effect ( $\varepsilon=0.9316, P=0.002$ ) on the ratio of applicant number to quota. The number of emergency patients was positive ( $\varepsilon=0.0309, P=0.421)$ and the closed programme was negative $(\varepsilon=-0.0096, P=0.644)$, but these were not statistically significant.

In the random effect model, the results were similar to those of the pooled OLS, and salary was not statistically significant. The $F$-test of the model specification was highly significant $(P<0.0001)$, in favor of the random effect model over the pooled OLS regression. The Breusch-Pagan test was also highly significant $(P<0.0001)$, suggesting that the fixed model was better than the pooled OLS regression results. Finally, the Hausman test showed a $P$-value equal to 0.0001, suggesting that the results of the fixed effect model are the most relevant to address unobserved heterogeneity among hospitals.

Because the ratio in a smaller quota programme is more susceptible to a change in the number of applicants, we also conducted least squares regression weighted by hospital size, and first difference estimation with dummy variables for hospital size, and found significant coefficients of salary (data not shown).

Table 3 shows the results of analyses stratified by the city size of the hospital location. The elasticity of the salary in the OLS $(\varepsilon=0.5787, P=0.027)$, the fixed effect model ( $\varepsilon=0.6498, P=0.036)$, and the random effect model ( $\varepsilon=0.5470, P=0.004)$, was positive and statistically significant in the small cities, but not significant in the large cities. When including an interaction term with the number of teaching physicians, however, the elasticity of salary became statistically significant and positive in the fixed effect model ( $\varepsilon=1.9089, P=0.016)$ and in the random effect model ( $\varepsilon=1.7051, P=0.004)$ in large cities, and the magnitude of the elasticity was comparable with that in small cities. The effect of the number of teaching physicians in the fixed effect model was positive and statistically significant, and

Table 1 Description of statistical sample

\begin{tabular}{|c|c|c|c|c|c|}
\hline \multirow[b]{2}{*}{ Variable } & \multicolumn{2}{|c|}{2006} & \multicolumn{2}{|c|}{2009} & \multirow[t]{2}{*}{$P$-value } \\
\hline & Mean & SD & Mean & SD & \\
\hline Ratio of the number of applicants to programme quota & 0.71 & 0.68 & 0.68 & 0.59 & 0.24 \\
\hline Salary (million yen, per 2 years) & 9.08 & 2.00 & 10.11 & 2.24 & $<0.001$ \\
\hline Number of teaching physicians (persons per 100 beds) & 10.4 & 3.1 & 10.4 & 3.7 & 0.92 \\
\hline Number of hospital beds & 433 & 173 & 424 & 167 & $<0.001$ \\
\hline Average number of inpatients (persons per day) & 375 & 153 & 348 & 148 & $<0.001$ \\
\hline Closed programme within a single institution (closed programme $=1$ ) & 0.27 & 0.45 & 0.14 & 0.34 & $<0.001$ \\
\hline Average number of emergency patients (persons per day per 10 beds) & 0.92 & 0.58 & 0.92 & 0.96 & 0.91 \\
\hline
\end{tabular}


Table 2 Multivariate analysis of the ratio of the number of applicants to programme quota by hospital characteristics

\begin{tabular}{lccc}
\hline Model & Ordinary least squares in 2009 & Fixed effect & Random effect \\
\hline Salary (million yen per 2 years) & Elasticity & Elasticity & Elasticity \\
\hline Number of teaching physicians (persons per 100 beds) & 0.0810 & $0.4995^{*}$ & 0.1480 \\
\hline Closed programme within a single institution (closed programme $=1)$ & $0.6211^{* *}$ & $0.3678^{* *}$ & $0.6908^{* *}$ \\
\hline Number of hospital beds (100 beds) & $0.0686^{* *}$ & -0.0096 & $0.0302^{*}$ \\
\hline Average number of emergency patients (persons per day per 10 beds) & $0.5154^{* *}$ & 0.0451 & 0.0309 \\
\hline Average number of inpatients (persons per day) & & $0.9316^{* *}$ & $0.0660^{*}$ \\
\hline
\end{tabular}

Number of hospitals $=475$.

${ }^{*} \mathrm{P}<0.05$.

${ }^{* *} \mathrm{P}<0.01$.

larger in the large cities $(\varepsilon=1.9857, P=0.009)$ compared with that in the small cities $(\varepsilon=1.6253, P=0.033)$. Finally, the elasticity of the interaction term was negative and statistically significant in the fixed effect model $(\varepsilon=-1.5223$, $P=0.038)$ and in the random effect model $(\varepsilon=-1.7013$, $P=0.003)$ in large cities. The elasticity of the interaction term in small cities was also negative and marginally significant $(\varepsilon=-1.4133, P=0.052$ for the fixed effect model; $\varepsilon=-0.9690, P=0.065$ for the random effect model).

The results of the $F$-test, the Breusch-Pagan test, and the Hausman test in all four models suggested that the results of the fixed effects model were more relevant than those in the OLS and the random effect model.

\section{Discussion}

We examined the effect of salary on residents' hospital choices. The results of pooled OLS were similar to those of Kawamura's previous results in that the coefficient of salary was positive and not significant [25]. However, the results of the fixed effect model were statistically significant, which were better supported by statistical specification tests. Basic characteristics of hospitals, such as hospital function,

Table 3 Elasticity of the stratified analyses by the population size of the hospital location

\begin{tabular}{|c|c|c|c|c|c|}
\hline \multirow[t]{2}{*}{ Model } & & \multicolumn{2}{|c|}{ Population $<279,127$} & \multicolumn{2}{|c|}{ Population $\geq 279,127$} \\
\hline & & Elasticity & Elasticity & Elasticity & Elasticity \\
\hline \multirow[t]{6}{*}{ Ordinary least squares } & Salary & $0.5787^{*}$ & 1.0390 & 0.0278 & 1.3582 \\
\hline & Number of teaching physicians & $0.5905^{* *}$ & 1.0740 & $0.5724^{* *}$ & $1.9154^{*}$ \\
\hline & Closed programme within a single institution & $0.1052^{* *}$ & $0.1042^{* *}$ & $0.0537^{* *}$ & $0.0543^{* *}$ \\
\hline & Number of hospital beds & $0.5751^{* *}$ & $0.5707^{* *}$ & $0.3919^{* *}$ & $0.3821^{* *}$ \\
\hline & Average number of emergency patients & 0.1163 & 0.1182 & 0.0315 & 0.0319 \\
\hline & Interaction (Salary*Number of teaching physicians) & & -0.5059 & & -1.3296 \\
\hline \multirow[t]{6}{*}{ Fixed effects model } & Salary & $0.6498^{*}$ & $1.9185^{* *}$ & 0.3842 & $1.9089^{*}$ \\
\hline & Number of teaching physicians & 0.1985 & $1.6253^{*}$ & $0.4521^{* *}$ & $1.9857^{* *}$ \\
\hline & Closed programme within a single institution & 0.0043 & 0.0056 & -0.0152 & -0.0114 \\
\hline & Number of inpatients & 0.2155 & 0.1951 & $1.5433^{* *}$ & $1.5960^{* *}$ \\
\hline & Average number of emergency patients & 0.0303 & 0.0053 & 0.0338 & 0.0370 \\
\hline & Interaction (Salary*Number of teaching physicians) & & -1.4133 & & $-1.5223^{*}$ \\
\hline \multirow[t]{6}{*}{ Random effects model } & Salary & $0.5470^{* *}$ & $1.4538^{* *}$ & 0.0083 & $1.7051^{* *}$ \\
\hline & Number of teaching physicians & $0.5900^{* *}$ & $1.5453^{* *}$ & $0.6793^{* *}$ & $2.3981^{* *}$ \\
\hline & Closed programme within a single institution & $0.0505^{*}$ & $0.0488^{*}$ & 0.0277 & 0.0307 \\
\hline & Number of inpatients & $0.8792^{* *}$ & $0.8692^{* *}$ & $0.5482^{* *}$ & $0.5413^{* *}$ \\
\hline & Average number of emergency patients & 0.1226 & 0.1231 & 0.0573 & $0.0585^{*}$ \\
\hline & Interaction (Salary*Number of teaching physicians) & & -0.9690 & & $-1.7013^{*}$ \\
\hline Number of hospitals & & 237 & 237 & 238 & 238 \\
\hline
\end{tabular}

${ }^{*} \mathrm{P}<0.05$.

${ }^{* *} \mathrm{P}<0.01$. 
location, and ownership, are supposed to determine the attractiveness of hospitals and the level of income simultaneously [30,43]. Therefore, results that control for this unobserved heterogeneity and endogenous relationship between hospital characteristics and salary level should more precisely identify the effect of salary on residents' choice of training hospitals.

Previous studies have also indicated that financial incentives would affect physicians' choice of training hospitals or workplace in high-income countries as well as in middle-low income countries [13-15,27,28]. A systematic review on human resource allocation in healthcare reported that increased wage for trainees may be an effective strategy to improve supply as well as distribution of physicians, though the validity of evidence was limited due to poor study design [15]. With a sophisticated statistical technique and use of panel data, our results have added a strong support to the statement that monetary incentive is a significant factor for a physician's choice of early career, especially in rural areas.

Our results also showed that the number of teaching physicians and that of inpatients had a positive effect on hospital choices. Previous studies also indicated that the quality of training environments, such as teaching skills of attending physicians and opportunities to learn clinical skills, was a significant factor that affected resident's choice of specialty and training location, and job satisfaction $[25,27,44,45]$. Although the number of teaching physicians does not necessarily guarantee the quality of teaching, busy attending physicians were reported to decrease residents' satisfaction with the quality of attending teaching in the US national survey of surgical residents [45]. The questionnaire survey by the MHLW in Japan also reported that in their choice of training, non-university residents took into consideration hospital factors, such as the number of clinical cases, to provide a sufficient learning experience (43.3\%), the comprehensiveness of the training curriculum (37.5\%), the number and quality of teaching physicians (29.7\%), and high-tech therapeutic equipment of hospital facilities (27.3\%) [27]. These conditions are expected to provide young residents with better opportunities to enhance their clinical skills and wider alternatives for career development.

In the current study in the analysis stratified by city size, the interaction term was statistically significant and negative in both groups, which suggested that the effects of salary and the number of teaching physicians were antagonistic. Therefore, the effect of salary was diminished when the number of teaching physicians was large. In addition, the magnitude of elasticity of the interaction and the number of teaching physicians were larger in large cities than those in small cities, suggesting that the antagonistic effect of the number of teaching physicians is larger in the urban setting. These results suggest that an increase in the number of teaching physicians may be a more effective strategy to attract residents in the urban setting than an increase in salary, while the increase in the number of teaching physicians may be a difficult alternative under the current shortage of physicians, especially in rural areas [46]. Offering a higher salary for young residents may be more feasible instead. Some previous studies argued that financial incentives alone are not sufficient, and that the strategy for staffing remote rural areas should be multi-facetted and comprehensive $[6,8,13]$. Our results rather indicated that resource could be strategically allocated between monetary incentives and training environments, according to local conditions.

Our study has several limitations. First, almost half of the hospitals included in the national residency programme were excluded from our sample because of the limitation in data availability. Because the submission of hospital information was voluntary, hospitals with a small-scale programme tended to be excluded from the Guidebook. We compared all the hospitals included in the Guidebook ( $\mathrm{n}=705$ in 2006, and 683 in 2009) with those included in our panel analysis. We found that the number of teaching physicians in 2006 was smaller in all the hospitals included in the Guidebook than those included in our panel analysis (10.11 persons versus 10.40 persons, $P=0.04$ ), and the number of inpatients was also smaller in 2006 and 2009 (in 2006, 359 versus 375 patients, $P=0.03$; in 2009, 332 versus 348 patients, $P=0.02$ ). Otherwise, the characteristics were comparable between the two datasets. In our study, the descriptive statistics on the number of hospital beds or doctors were similar to those of Kawamura's study, which had a cross-sectional and larger sample than that in our study [25]. However, in 2009 in the university-affiliated hospitals, the average number of beds was 596, the average number of outpatients was 977 per day, and the average number of doctors was 47 per 100 hospital beds [47]; these numbers were much larger than in our sample. Therefore, we acknowledge that our estimation of the effect of salary in non-university hospitals may not necessarily hold true in the university hospitals. We also cannot deny the possibility that our results may have limited generalizability, and these should be confirmed with longer-term and larger panel data from teaching hospitals in the country.

Second, the natural change in residents' preferences over the studied period could have affected our results. For example, the number of female physicians has been continuously increasing to more than $30 \%$ of newly qualified physicians [48]. Sex is significantly related to a resident's choice of a university hospital as a training site [28], and also with the likelihood of satisfaction with salary [49]. Because the number of residents by sex was not available, we could not account for the effect of the resident's sex in our analysis. The results of this study should be confirmed with sex-specific datasets, or more preferably, with microdata of residents' preferences. 


\section{Conclusions}

Our results show that an increase in salary has a positive and significant effect on a resident's choice of training hospital among non-university institutions. The conditions of monetary reward in a residency programme are a possible tactic for hospitals to attract residents.

\section{Abbreviations}

JRMP: Japan Residency Matching Programme; MHLW: Ministry of Health, Labour, and Welfare; OLS: ordinary least squares; PMEP: Postgraduate Medical Education Programme.

\section{Competing interests}

The authors declare that they have no competing interests.

\section{Authors' contributions}

TE designed the study, collected the data, and analyzed and interpreted the data. TE wrote the first draft of the manuscript. HH supervised the study and critically reviewed the manuscript. TE and $\mathrm{HH}$ read and approved the final manuscript.

\section{Acknowledgements}

We thank the Foundation for Promotion of Medical Training for providing data on participating programmes and affiliated institutions. We also acknowledge Prof. Motohiro Sato for his guidance in the early part of the study, and Dr Akira Kawamura for his previous work and constructive comments on analytical methods. We also acknowledge that the review comments from Drs James Buchan, Kyoko Nomura, and Giuliano Russo considerably helped us improve the manuscript. This study received no financial support.

Received: 18 January 2012 Accepted: 18 February 2013

Published: 8 March 2013

\section{Reference}

1. Rivo ML, Kindig DA: A report card on the physician work force in the United States. N Engl J Med 1996, 334:892-896.

2. Rosenthal MB, Zaslavsky A, Newhouse JP: The geographic distribution of physicians revisited. Health Serv Res 2005, 40:1931-1952.

3. Hann $M$, Gravelle $H$ : The maldistribution of general practitioners in England and Wales: 1974-2003. Br J Gen Prac 2004, 54:894-898.

4. Barer ML, Stoddart GL: University of British Columbia. Health Human Resources Unit: Improving access to needed medical services in rural and remote Canadian communities: recruitment and retention revisited. British Columbia: Centre for Health Services and Policy Research, University of British Columbia; 1999.

5. Russo G, Ferrinho P, De Sousa B, Conceição $C$ : What influences national and foreign physicians' geographic distribution? An analysis of medical doctors' residence location in Portugal. Hum Resour Health 2012, 10:12. doi:10.1186/1478-4491-10-12.

6. Girasek E, Eke E, Szócska M: Analysis of a survey on young doctors' willingness to work in rural Hungary. Hum Resour Health 2010, 8:13. doi:10.1186/1478-4491-8-13.

7. Laurence C, Elliott T: When, what and how South Australian preregistration junior medical officers' career choices are made. Med Educ 2007, 41:467-475.

8. Lehmann U, Dieleman M, Martineau T: Staffing remote rural areas in middle- and low-income countries: a literature review of attraction and retention. BMC Health Serv Res 2008, 8:19. doi:10.1186/1472-6963-8-19.

9. Dussault G, Franceschini MC: Not enough there, too many here: understanding geographical imbalances in the distribution of the health workforce. Hum Resour Health 2006, 4:12. doi:10.1186/1478-4491-4-12.

10. Bourgueil Y, Mousques J, Tajahmadi A: Improving the geographical distribution of health professionals: What the literature tells us. [http://www. hrhresourcecenter.org/node/1636]

11. Kobayashi Y, Takaki H: Geographic distribution of physicians in Japan. Lancet 1992, 340:1391-1393.

12. Tanihara S, Kobayashi Y, Une H, Kawachi I: Urbanization and physician maldistribution: a longitudinal study in Japan. BMC Health Serv Res 2011, 11:260. doi:10.1186/1472-6963-11-260.
13. Sempowski IP: Effectiveness of financial incentives in exchange for rural and underserviced area return-of-service commitments: systematic review of the literature. Can J Rural Med 2004, 9:82-88.

14. Barnighausen T, Bloom DE: Financial incentives for return of service in underserved areas: a systematic review. BMC Health Serv Res 2009, 9:86. doi:10.1186/1472-6963-9-86.

15. Chopra M, Munro S, Lavis JN, Vist G, Bennett S: Effects of policy options for human resources for health: an analysis of systematic reviews. Lancet 2008, 371:668-674.

16. Adler R, Korsch BM, Negrete VF: Timing and motivation in pediatric career choices. Acad Med 1985, 60:174-180.

17. Kazzi AA, Langdorf MI, Ghadishah D, Handly N: Motivations for a career in emergency medicine: a profile of the 1996 US applicant pool. CJEM 2001, 3:99-104.

18. Schwartz MD, Linzer M, Babbott D, Divine GW, Broadhead E: Medical student interest in internal medicine. Initial report of the Society of General Internal Medicine Interest Group Survey on Factors Influencing Career Choice in Internal Medicine. Ann Intern Med 1991, 114:6-15.

19. McMurray JE, Schwartz MD, Genero NP, Linzer M: The attractiveness of internal medicine: a qualitative analysis of the experiences of female and male medical students. Ann Intern Med 1993, 119:812-818.

20. Erzurum VZ, Obermeyer RJ, Fecher A, Thyagarajan P, Tan P, Koler AK, Hirko MK, Rubin JR: What influences medical students' choice of surgical careers. Surgery 2000, 128:253-256.

21. Newton DDA: What predicts medical student career choice? J Gen Intern Med 1998, 13:200-203.

22. Kassler WJ, Wartman SA, Silliman RA: Why medical students choose primary care careers. Acad Med 1991, 66:41-43.

23. Scott A: Eliciting GPs' preferences for pecuniary and non-pecuniary job characteristics.J Health Econ 2001, 20:329-347.

24. Newton DA, Grayson MS, Thompson LF: The Variable Influence of Lifestyle and Income on Medical Students' Career Specialty Choices: Data from Two U.S. Medical Schools, 1998-2004. Acad Med 2005, 80:809-814.

25. Kawamura A: Determinant factors of residency faculties in newly graduated medical doctors (Shinsotsu ishi no kenshuusaki kettei youin). Byoin 2009, 68:1005-1009 [in Japanese]

26. Koike $S$, Kodama T, Matsumoto $S$, Ide H, Yasunaga H, Imamura T: Residency hospital type and career paths in Japan: an analysis of physician registration cohorts. Med Teach 2010, 32:239-247.

27. Ministry of Health, Labour and Welfare: Final report on the survey about clinical residency (Rinsho kenshu ni kansuru chosa: saishu hokoku). [http://www.mhlw.go. jp/topics/bukyoku/isei/rinsyo/chosa-saisyu06/index.html][in Japanese].

28. Nomura K, Yano E, Mizushima S, Endo H, Aoki M, Shinozaki H, Fukui T: The shift of residents from university to non-university hospitals in Japan: a survey study. J Gen Intern Med 2008, 23:1105-1109.

29. Ministry of Health, Labour and Welfare: Minutes of Medical Residency Subcommittee. [http://www.mhlw.go.jp/shingi/2009/12/dl/s1218-13b.pdf] [in Japanese]

30. Hay JW: Physician's specialty choice and specialty income. In Econometrics of Health Care. Edited by Duru G, Paelinck JHP. Dordrecht: Kluwer Academic Publishers; 1991:95-113.

31. Ministry of Health, Labour and Welfare: The treatments conditions of the residents in training hospitals. (Rinsho byoin ni okeru kenshui no shoguu). [http://www.mhlw.go.jp/stt/shingi/2r9852000001vj46-att/2r9852000001vj7i. pdf][in Japanese]

32. Thornton J, Esposto F: How important are economic factors in choice of medical specialty? Health Econ 2003, 12:67-73.

33. Nomura K, Yano E, Aoki M, Kawaminami K, Endo H, Fukui T: Improvement of residents' clinical competency after the introduction of new postgraduate medical education program in Japan. Med Teach 2008, 30:161-169.

34. Inoue K, Matsumoto M: Japan's new postgraduate medical training system. Clin Teach 2004, 1:38-40.

35. Kozu T: Medical education in Japan. Acad Med 2006, 81:1069-1075.

36. Koike S, Ide H, Yasunaga H, Kodama T, Matsumoto S, Imamura T: Postgraduate training and career choices: an analysis of the National Physicians Survey in Japan. Med Educ 2010, 44:289-297.

37. Published Data on Japan Residency Matching Program. [http://www.jrmp.jp/ data.htm][in Japanese].

38. Guidebook on Medical Residency Hospitals ver. 2010 [http://www.jrmp.jp/ hospital.htm] 
39. Guidebook on Medical Residency Hospitals ver. 2007 [http://www.jrmp.jp/ hospital.htmin][in Japanese].

40. National Statistics Center: Resional Statistics. [http://www.e-stat.go.jp/SG1/ estat/eStatTopPortalE.do]

41. Hashimoto H, Ikegami N, Shibuya K, Izumida N, Noguchi H, Yasunaga H, Miyata H, Acuin JM, Reich MR: Cost containment and quality of care in Japan: is there a trade-off? Lancet 2011, 378:1174-1182.

42. Wooldridge JM: Econometric analysis of cross section and panel data. Cambridge: The MIT press; 2002.

43. Hurley JE: Physicians' Choices of Specialty, Location, and Mode. J Hum Resour 1991, 26:47-71.

44. Davenport DL, Henderson WG, Hogan S, Mentzer RM, Zwischenberger JB: Surgery resident working conditions and job satisfaction. Surgery 2008, 144:332-338.

45. Ko CY, Escarce JJ, Baker L, Sharp J, Guarino C: Predictors of surgery resident satisfaction with teaching by attendings: a national survey. Ann Surg 2005, 241:373-380.

46. Koike $\mathrm{S}$, Yasunaga $\mathrm{H}$, Matsumoto $\mathrm{S}$, Ide $\mathrm{H}$, Kodama $\mathrm{T}$, Imamura T: A future estimate of physician distribution in hospitals and clinics in Japan. Health Policy 2009, 92:244-249.

47. Ministry of Health, Labour and Wealth: Hospital Report. 2009 [http://www.estat.go.jp/SG1/estat/NewList.do?tid=000001030749][in Japanese].

48. Ministry of Health, Labor, and Welfare: Survey of physicians, dentists, and pharmacists. 2008 [http://www.mhlw.go.jp/toukei/saikin/hw/ishi/08/index. $\mathrm{html}][$ in Japanese]

49. Nomura K, Yano E, Fukui T: Gender differences in clinical confidence: A nationwide survey of resident physicians in Japan. Acad Med 2010, 85:647-653.

doi:10.1186/1478-4491-11-12

Cite this article as: Enari and Hashimoto: Does salary affect the choice of residency in non-university teaching hospitals? A panel analysis of Japan Residency Matching Programme data. Human Resources for Health 2013 11:12.

\section{Submit your next manuscript to BioMed Central and take full advantage of:}

- Convenient online submission

- Thorough peer review

- No space constraints or color figure charges

- Immediate publication on acceptance

- Inclusion in PubMed, CAS, Scopus and Google Scholar

- Research which is freely available for redistribution 